Article

\title{
Why Healthcare and Education Professionals Underreport Suspicions of Child Abuse: A Qualitative Study
}

\author{
Jeanne Gubbels $^{1, *(\mathbb{D}}$, Mark Assink ${ }^{1} @$, Peter Prinzie ${ }^{2}$ and Claudia E. van der Put $^{1}$ \\ 1 Research Institute of Child Development and Education, University of Amsterdam, 1018 WS Amsterdam, \\ The Netherlands; M.Assink@uva.nl (M.A.); C.E.vanderPut@uva.nl (C.E.v.d.P.) \\ 2 Erasmus School of Social and Behavioral Sciences, Department of Psychology, Education \& Child Studies, \\ Erasmus University Rotterdam, 3062 PA Rotterdam, The Netherlands; Prinzie@essb.eur.nl \\ * Correspondence: J.Gubbels@uva.nl
}

Citation: Gubbels, Jeanne, Mark Assink, Peter Prinzie, and Claudia E. van der Put. 2021. Why Healthcare and Education Professionals Underreport Suspicions of Child Abuse: A Qualitative Study. Social Sciences 10: 98. https://doi.org/ 10.3390/socsci10030098

Academic Editor: Nigel Parton

Received: 1 February 2021

Accepted: 4 March 2021

Published: 10 March 2021

Publisher's Note: MDPI stays neutral with regard to jurisdictional claims in published maps and institutional affiliations.

Copyright: (C) 2021 by the authors Licensee MDPI, Basel, Switzerland. This article is an open access article distributed under the terms and conditions of the Creative Commons Attribution (CC BY) license (https:// creativecommons.org/licenses/by/ $4.0 /)$.

\begin{abstract}
Education and healthcare professionals are crucial in detecting and reporting child abuse and neglect. However, signs of child abuse are often undetected, and professionals tend to underreport their suspicions of abuse and neglect. This qualitative study aimed to examine experiences, attitudes, perspectives, and decision-making skills of healthcare and education professionals with regard to identifying and reporting child abuse and to gain insight into how detection and reporting can be improved. Semi-structured interviews were conducted with 49 Dutch professionals working in child health care, mental health care, primary schools, and secondary schools. The I-Change model was used as a theoretical framework to organize the results. Many professionals believe they miss child abuse signs in their daily work, partially due to a lack of focus on child abuse. Further, professionals indicated having insufficient knowledge of child abuse, and lack communication skills to detect or discuss signs indicative of child abuse in conversations with parents or children. As for risk assessment, professionals barely use structured instruments even though these are regarded as very helpful in the decision-making process. Finally, professionals experience deficits in the cooperation with child welfare organizations, and in particular with Child Protective Services (CPS). Various directions for improvement were discussed to overcome barriers in child abuse detection and reporting, including developing tools for detecting and assessing the risk of child abuse and improving communication and information transfer between organizations.
\end{abstract}

Keywords: child abuse; detection; reporting; health care professionals; education professionals

\section{Introduction}

Child abuse is a major public health problem with potentially devastating and long-term effects on children (Alink et al. 2012; Cicchetti 2016; Gilbert et al. 2009a; Jonson-Reid et al. 2012). Early detection of (risks of) child abuse is essential to effectively prevent and reduce child abuse. School teachers and child healthcare professionals play a crucial role in the detection and reporting of child abuse, because they encounter almost all children in the population during their daily work. However, studies show that healthcare and education professionals underreport their suspicions of child abuse (Goebbels et al. 2008; Reijneveld et al. 2008; Visscher and Van Stel 2017). In the Netherlands, child abuse is reported by professionals for approximately three percent of all Dutch children (Alink et al. 2018), whereas self-report studies show a child abuse prevalence of 12 percent (Schellingerhout and Ramakers 2016). This difference in percentages implies that most child abuse cases in the Netherlands are not detected by professionals. Furthermore, results from an inspection report show that many cases of child abuse are missed by Dutch education and healthcare professionals (Health Care Inspectorate 2017). Therefore, it is important to gain knowledge on how detecting and reporting child abuse of professionals can be improved. The aim of this qualitative study was to examine the experiences, attitudes, perspectives, and decision-making skills of 
healthcare and education professionals with regard to identifying and reporting child abuse and to gain insight into how detection and reporting can be improved.

In many countries, such as the United States (Child Welfare Information Gateway 2019) Australia (The Council of Australian Governments 2009), and almost all European countries (European Union Agency for Fundamental Rights 2017), professionals are legally obliged to report suspicions of child abuse and neglect to Child Protective Services (CPS). International research shows, however, that the underreporting of child abuse is rather common among education and health care professionals, such as public child healthcare nurses (Fraser et al. 2010), social services professionals (Cerezo and Pons-Salvador 2004), orthopedic surgeons (Lane and Dubowitz 2007), school teachers (Goebbels et al. 2008; Webster et al. 2005), and kindergarten teachers (Feng et al. 2010). Therefore, the number of reported child abuse cases is often referred to as the "tip of the iceberg" (Chang et al. 2004; De Haan et al. 2019). Greco et al. (2017) for example examined the reporting behaviors of 184 school staff members and found that more than $74 \%$ of staff members had suspected at least one situation of victimization during their careers, but only $27 \%$ had actually reported these suspicions. Further, Feng et al. (2010) found in a sample of 598 Taiwanese kindergarten teachers that $97 \%$ had no experience with reporting a child abuse case, and $11 \%$ indicated that they had suspected at least one incident of child abuse but did not report the case.

Various sociological and cultural factors affect professionals' reporting behaviors, including the education they received, their cultural background or their own childhood and parenting experiences. Furthermore, laws and regulations influence professionals' reporting. In the Netherlands, professionals working with children and families are not legally required to report suspicions but need to follow specific reporting guidelines when they suspect child abuse and neglect (Ministry of Health, Welfare and Sport 2013). These guidelines describe the following five steps that aim to help professionals in deciding whether or not suspicions of potential child abuse should be reported: (1) identifying signs of child abuse, (2) consulting colleagues, (3) discussing the identified child abuse signs with those involved (parents and/or children), (4) assessing the nature and severity of the abuse, and (5) deciding on organizing professional care and reporting the potential abuse. Since 1 July, 2013, the Mandatory Reporting Code Act came into force in the Netherlands, obligating organizations in health care, child and youth care, day care, social support, criminal justice, and education to use these guidelines and to promote the use of the reporting guidelines among professionals (Ministry of Health, Welfare and Sport 2013). However, research shows that professionals working with children insufficiently use these mandatory guidelines as they are not aware of the individual steps or do not identify sigs of child abuse (Health Care Inspectorate 2017). Furthermore, the results from the evaluation of the mandatory guidelines suggest that Dutch professionals that are obliged to work with these guidelines find it difficult to detect signs of child abuse, especially signs that are less visible, and are therefore not able to continue with the rest of the steps (Ridderbos-Hovingh et al. 2020).

Insufficient child abuse detection and reporting by healthcare and education professionals is problematic, as in particular these groups of professionals play an essential role in reducing child abuse. Professionals in the Dutch child health care system (CHC; e.g., nurses and pediatricians) offer preventive child health care services in child health clinics and schools (Konijnendijk et al. 2014). As approximately 95\% of the Dutch children see a CHC professional on a regular basis (Reijneveld et al. 2008), these professionals can have an essential role in recognizing and responding to (suspicions of) child abuse. Further, professionals in mental health care also have an important task in identifying and reporting child abuse, despite their minimum contact with children. Both perpetrators and victims of child abuse are at high risk of coming into contact with mental health care during their lifetime, as parental mental health problems are important predictors for child abuse (Assink et al. 2019; Mulder et al. 2018) and victimization of child abuse itself is an important risk factor for mental health problems later in life (Alink et al. 2012; Gilbert et al. 2009a). Moreover, in $43 \%$ of all child abuse cases, a parent with a mental health or substance abuse disorder is involved (Kinderrechtencolleftief 2011). Finally, teachers and other primary and secondary 
school professionals are in a unique position to detect child abuse given their daily contact with children. This allows them to observe changes in children's behavior and appearance (Gilbert et al. 2009b). In addition, teachers are relatively close to the parents of their pupils, so they have at least some insight into the parent-child relationship (Schols et al. 2013).

Furthermore, previous studies indicate that healthcare and education professionals experience barriers in detecting and reporting child abuse, such as a lack of knowledge about the signs of child abuse. Professionals point to a lack of pre- and post-service training on how to signal different forms of child abuse. Further, experiencing fear is an important barrier in detecting and reporting child abuse. This refers to the fear of potential negative consequences of a child abuse report for a child as well as the fear of losing the trust of parents (Gilbert et al. 2009b; Greco et al. 2017). Finally, professionals find it quite difficult to discuss their suspicions or signs of child abuse with children and/or parents, which is one of the most important barriers in the reporting process (Schols et al. 2013).

To investigate how public health nurses, physicians, and primary school teachers detect and report child abuse, qualitative research was carried out by Schols et al. (2013). They concluded that, although professionals are generally aware of signs of child abuse, there is a lack of specialized knowledge and a need for instruments to help professionals in detecting child abuse. After Schols et al. (2013) finalized their study, the aforementioned Mandatory Reporting Code Act became effective in the Netherlands, which may have affected the way professionals detected child abuse and acted upon suspicions of child abuse. To find out what the implementation of the mandatory reporting guidelines means for detecting and reporting behaviors of professionals, a follow-up study is needed.

Therefore, the current qualitative research was conducted to gain insight into how professionals in $\mathrm{CHC}$, adult mental health care, primary education, and secondary education, detect and report child abuse after the implementation of the child abuse reporting guidelines became required by the Dutch law. In addition to Schols et al. (2013) who identified various barriers in signaling and reporting of child abuse experienced by public child healthcare professionals and primary school teachers, we also examined how professionals think that the detection and reporting of child abuse can be improved. Furthermore, in addition to child healthcare and primary school professionals, we also included mental health care and high school professionals in the current study.

Following Schols et al. (2013), the detection and reporting behaviors of professionals were investigated with the Integrated Model for Behavioral Change (I-Change model; (De Vries et al. 2005; De Vries 2017)). This model describes factors that influence any behavioral change process, and integrates concepts from the Social Cognitive Theory (Bandura 1986), Theory of Planned Behavior (Ajzen 1991), the Transtheoretical Model (Prochaska and DiClemente 1983), the Health Belief Model (Janz and Becker 1984), and Implementation and Goal Setting Theories (Locke and Lathan 1991). According to the I-Change model, change in behavior is achieved in three phases: (1) awareness phase, (2) motivation phase, and (3) the action phase. In this model, it is assumed that a person's abilities, such as being able to prepare and execute specific plans to reach the goal behavior (i.e., reporting child abuse in the current study), as well as actual behavioral skills will increase the likelihood that intentions are transferred into actions, whereas barriers can reduce this likelihood. According to the model, someone's intentions are directly influenced by motivational factors, such as social influences (social norms and the degree of social support in acting upon suspicions of child abuse), self-efficacy (the belief in one's own ability to achieve the behavior), and attitude (perceived cognitive and emotional advantages and disadvantages of the behavior). These motivational factors are in turn determined by various distal factors, such as awareness factors (including knowledge and risk perception), predisposing factors (such as someone's personality, gender, and lifestyle), and factors related to the information that someone takes in (e.g., the quality of messages or sources). The I-Change model applied to the current study allows us to distinguish factors that underlie professionals' decisions to report or act upon suspected child abuse. Moreover, our choice was also guided by the broad applicability of this 
model. The I-Change Model has been used in different fields and to study for instance various health (risk) behaviors (Cheung et al. 2021; Eggers et al. 2014; Segaar et al. 2006), as well as behaviors of health professionals (Goebbels et al. 2008; Ketterer et al. 2014; Schols et al. 2013). Goebbels et al. (2008) used the I-Change model to examine teachers' reporting behaviors, and a similar model based on the Theory of Planned Behavior was used to identify factors associated with the intention to report child abuse among nurses and kindergarten teachers in Taiwan (Feng et al. 2010; Feng and Wu 2005). Therefore, we consider the I-Change model to be a good conceptual framework to organize the results of the current study.

\section{Methods}

\subsection{Participants}

Semi-structured interviews were conducted with 49 professionals, including $15 \mathrm{CHC}$ professionals, 10 mental health care professionals, 14 primary school professionals, and 10 secondary school professionals. The CHC professionals worked as a nurse $(n=10)$ or pediatrician $(n=5)$ in various $\mathrm{CHC}$ centers in the Netherlands. Their average work experience was 15.5 years, with the pediatricians having more experience $(M=21.2)$ than the nurses $(M=12.7)$. Seven professionals also held the position of child abuse expert in their organization, meaning that they are responsible for the implementation of the reporting guidelines and the coordination of the processes related to signaling and reporting (potential) child abuse. The mental health professionals fulfilled the positions of clinician/therapist, individual or group counselor, clinical case manager, and/or team leader. Their average work experience was 7.2 years and they worked in outpatient clinics, intensive care departments, substance abuse clinics, or forensic care facilities. The primary school professionals worked as school counselors or teachers and in regular $(n=11)$ or special primary education $(n=3)$. Their average work experience was 8 years. Finally, the high school professionals worked an average of 10.1 years as school counselor $(n=7)$, psychologist $(n=2)$, or social worker $(n=1)$ and in regular $(n=8)$ or special secondary education $(n=2)$.

\subsection{Procedure}

Professionals were recruited by contacting the organizations that participate in the consortium research project that resulted in the current study. An e-mail was sent to relevant institutions and schools, including an explanation of this study and the call for professionals to share their experiences with detecting and reporting child abuse in a semistructured interview. The professionals who volunteered to participate received detailed information on research participation, after which the interview was scheduled.

The interviews were conducted by the first author of this study, together with one of four master degree students. Prior to the interviews, the students were instructed on how to conduct the semi-structured interviews and, if necessary, received further instructions based on the first interviews they completed. All interviews lasted about $45 \mathrm{~min}$ and took place at professionals' workplace. The interviews started with a brief introduction of the study. Professionals were asked for permission to record the interview and informed that all personal data was anonymized for this study. The professionals were given the opportunity to ask questions before the interview began. The Ethics Committee of the Faculty of Social and Behavioral Sciences of the University of Amsterdam approved this study (project number 2020-CDE-11642).

\subsection{Instruments}

An interview guide was used during the semi-structured interviews (available from the corresponding author on request), which were based on the three phases of the IChange model (De Vries et al. 2005). "Examples of interview questions are: "How do you detect child abuse in your daily work?" and "How do you determine the nature and severity of potential child abuse?". The interview questions were generally the same for the 
different types of professionals, although there were some differences as some questions were only relevant for specific professionals. Prior to the interviews, a pilot interview was held after which the questionnaire was adjusted and finalized.

\subsection{Data-Analysis}

Audio recordings were made during the interviews which were transcribed and coded using the software program ATLAS.ti version 8. Coding was performed in three stages: open coding, axial coding, and selective coding (Boeije 2009; Strauss and Corbin 2007). First, all interviews were carefully read and each relevant fragment was provided with a code (open coding). Second, all fragments of each interview were compared to identify overlapping themes (axial coding), which corresponded to the topics in the questionnaires. Finally, the themes from the axial phase were compared and connections were made between these themes in networks (selective coding). These networks provided insight into the contradictions and similarities between different codes. Based on these networks three concept maps were created, which are depicted in Figures 1-3. The I-Change model was used as a theoretical framework in identifying important themes. All interviews were coded by the first author of this study as well as by four master degree students. The first author resolved any inconsistency in coding after which the final coding was reached.

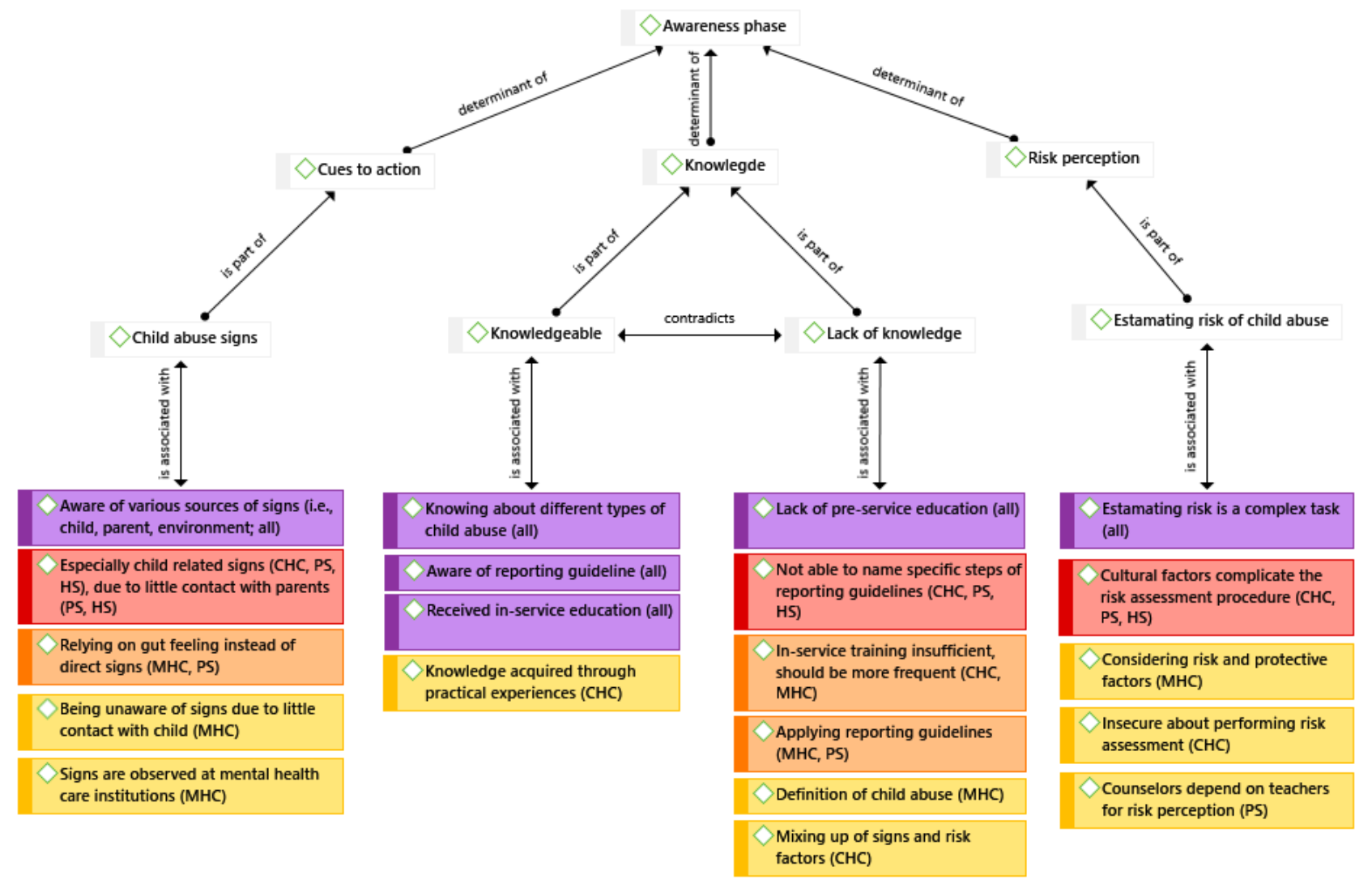

Figure 1. A concept map of the results as related to the awareness phase of the I-Change model. The labels on the second level refer to the determinants of the awareness phase, the labels on the third level refer to the key themes, and the labels on the fourth level refer to the subthemes. Subthemes with purple labels are relevant for all groups of professionals, subthemes with red labels are relevant for three groups, subthemes with orange labels for two groups, and subthemes with yellow subtheme for one group of professionals. The specific groups of professionals for which the subthemes were applicable, are presented in parentheses. $\mathrm{CHC}=$ child health care professionals; $\mathrm{MHC}=$ mental health care professionals; $\mathrm{PS}=$ primary school professionals; HS = high school professionals. 


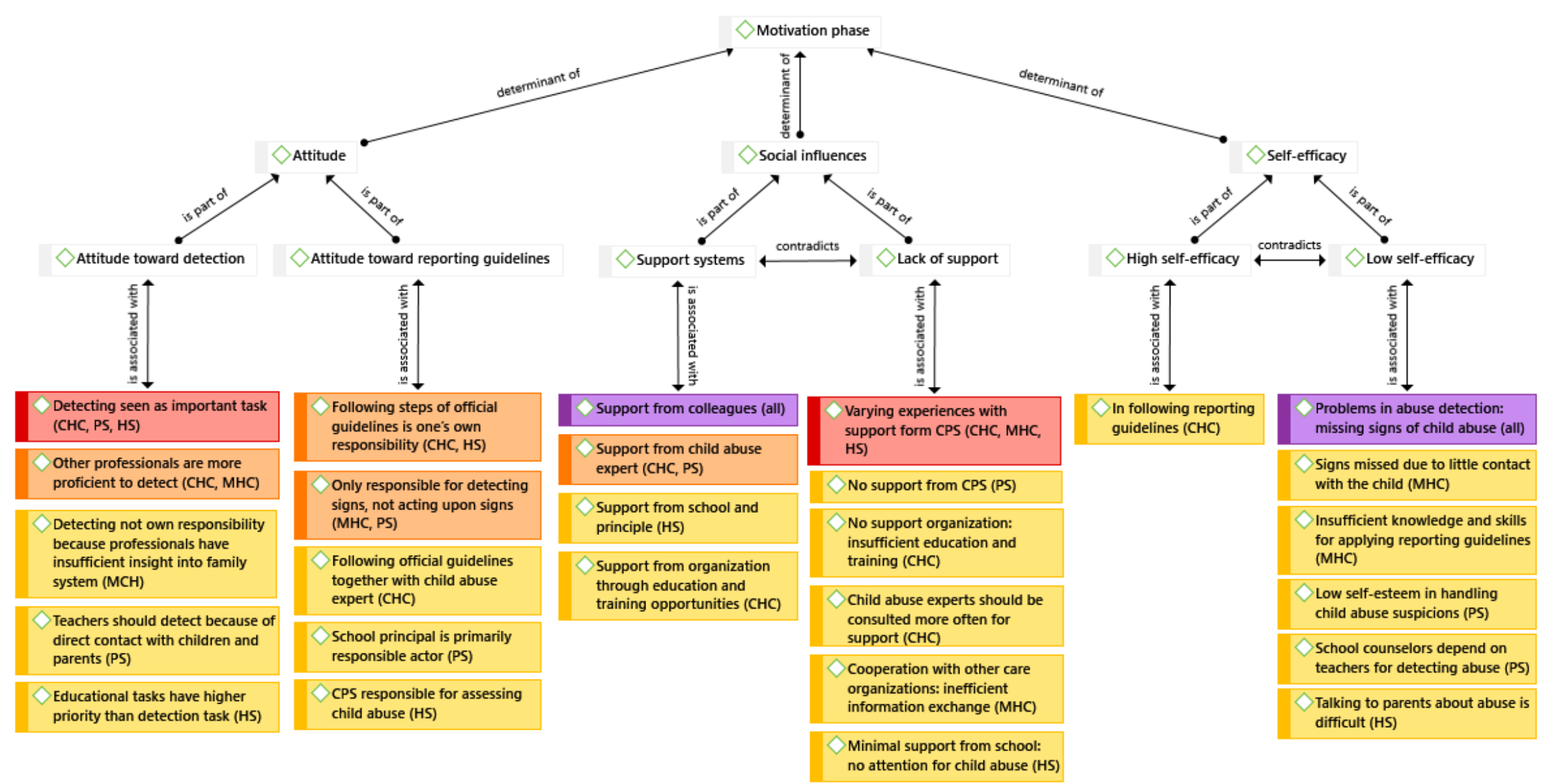

Figure 2. A concept map of the results as related to the motivation phase of the I-Change model. The labels on the second level refer to the determinants of the motivation phase, the labels on the third level refer to the key themes, and the labels on the fourth level refer to the subthemes. Subthemes with purple labels are relevant for all groups of professionals, subthemes with red labels are relevant for three groups, subthemes with orange labels for two groups, and subthemes with yellow subtheme for one group of professionals. The specific groups of professionals for which the subthemes were applicable, are presented in parentheses. $\mathrm{CHC}=$ child health care professionals; $\mathrm{MHC}=$ mental health care professionals; $\mathrm{PS}=$ primary school professionals; HS = high school professionals. 


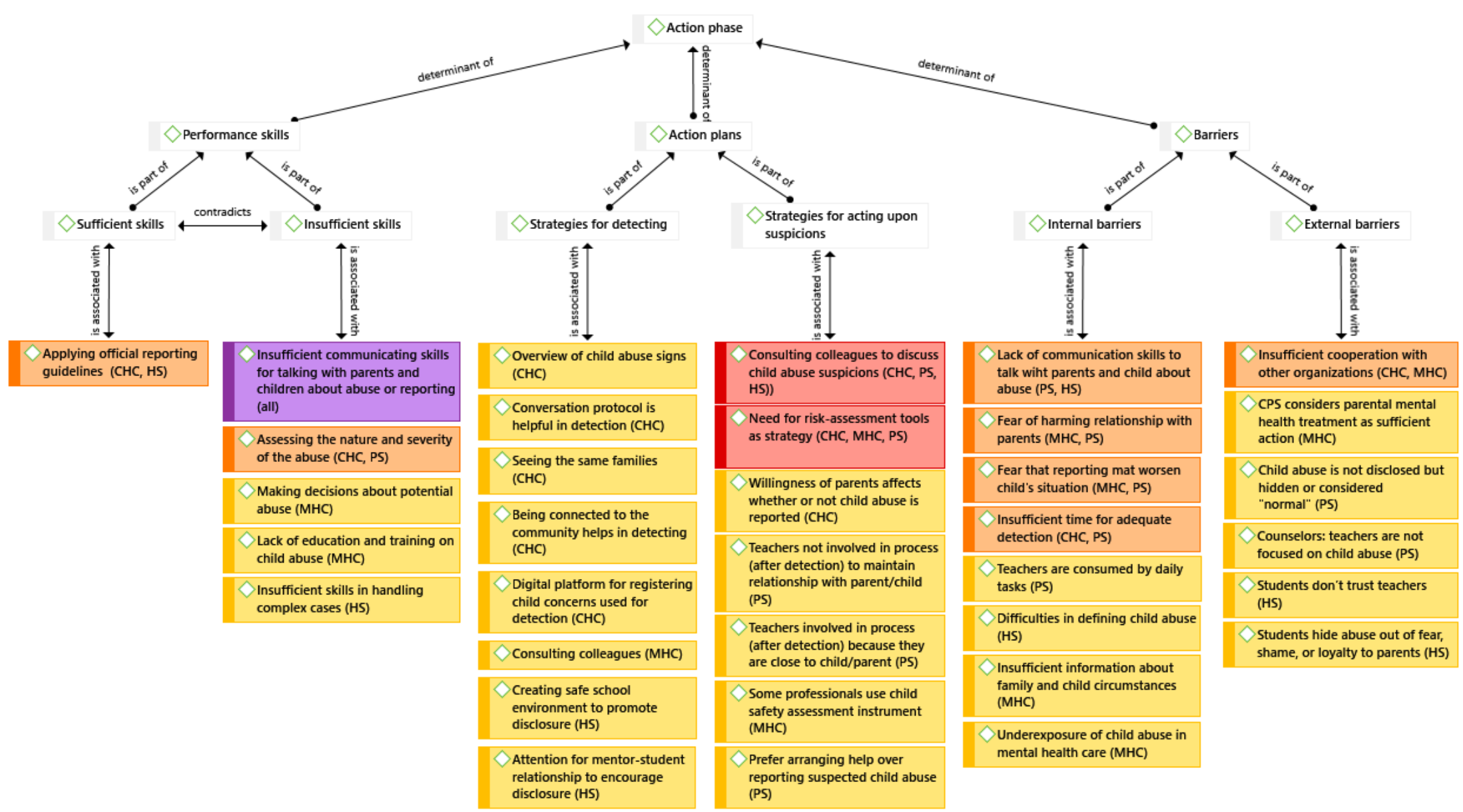

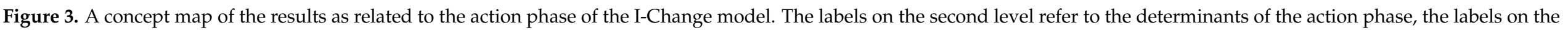

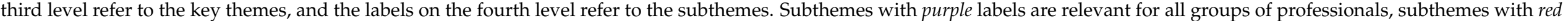

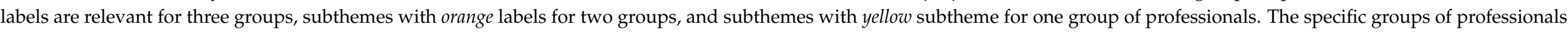

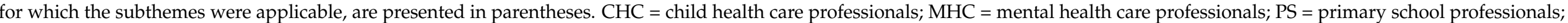
HS = high school professionals. 


\section{Results}

The results are presented following the phases of the I-Change model: the awareness phase, the motivation phase, and the action phase (De Vries et al. 2005). At the end of this section we describe how professionals would improve their detection and reporting of child abuse.

\subsection{Awareness Phase}

According to the I-Change model awareness is the result of accurate knowledge and risk perceptions of a person about his own behavior and the presence of cues to action in their environment (De Vries et al. 2005). Figure 1 provides a concept map of the results as related to the awareness phase of the I-Change model.

\subsubsection{CHC Professionals}

Cues to Action. CHC professionals are aware of many different child abuse signs from different sources, such as the child (e.g., developmental delays, bruises), the parent (e.g., parental stress), the parent-child interaction (e.g., ignoring the child), and the child's environment (e.g., financial problems in the family). Signs originating from the child are mentioned more often than other sources. However, one professional said: "Child related signs emerge much later when it comes to child abuse, so I'll keep that in mind". Parent related signs are mentioned the least.

Knowledge. CHC professionals are aware of various signs and risk factors for child abuse, but tend to mix up these terms. They do know the signs corresponding to different types of child abuse. Professionals are aware of the reporting guidelines and indicate that they have sufficient knowledge and skills to follow these guidelines. However, they are not able to name the specific steps of the reporting guidelines. A professional said about this: "I do not encounter a child abuse case every week, so I cannot recall every individual step of the reporting guidelines". Further, professionals did not receive any pre-service child abuse education, but acquired knowledge on child abuse through practical experience and some in-service education programs. These in-service programs are considered as valuable in improving child abuse detection. However, professionals mention that these in-service programs take place only once or twice a year, and they indicate that more child abuse education is needed.

Risk perception. Assessing the risk of child abuse is considered difficult by all $\mathrm{CHC}$ professionals, and they all indicate feeling insecure about performing risk assessments. Cultural factors in children and their families may further complicate the risk assessment process. A professional said about this: "I know that for example child spanking is considered as normal parenting behavior in cultures other than my own. Should I consider child spanking as child abuse? What perspective should I take on this as a CHC professional?".

\subsubsection{Mental Health Care Professionals}

Cues to Action. Not every mental health care professional is aware of child abuse signs because of limited contact with children. The professionals indicate that they mostly rely on their gut feeling in detecting child abuse. Other mental health professionals are aware of child related signs, such as bruises, aggressive behavior, or withdrawn behavior. Parent related signs were also mentioned, such as intimidating behavior or parental stress. Potential child abuse signs are detected during contact moments between patients and their children at the mental healthcare institution.

Knowledge. Professionals are able to name several types of child abuse. Defining child abuse and deciding whether or not a child is being abused was considered difficult by some professionals. Most professionals are aware of the reporting guidelines, but not all professionals use these guidelines in their daily work. Only four mental health care professionals feel that they are competent in applying the reporting guidelines during their work. Furthermore, professionals barely receive any pre-service child abuse education, which is considered important in improving child abuse prevention. Most mental health care 
professionals acquired knowledge on child abuse signs through several courses. However, these courses should be repeated more often to significantly contribute to improvements in child abuse detection.

Risk Perception. Several risk (e.g., parental alcohol abuse) and protective (e.g., openness to accept help, good relationship with grandparents) factors are taken into account by most mental healthcare professionals in assessing the nature and severity of child abuse. Performing risk assessment is however considered difficult by most professionals. One professional said: "When should I alert people? How do I decide whether signs point to child abuse or not? I think this will always be vague".

\subsubsection{Primary School Professionals}

Cues to Action. Primary school professionals are aware of various child abuse signs. Especially child related signs are used in detecting child abuse, including bruises, children wearing clothes that are too small or not appropriate (e.g., short skirts in winter), or not bringing food to school. Signs originating from the parents included parents letting children go to school alone, parents not picking up children from school and parents who are often sick. Cues related to parent-child interaction were also mentioned. Some professionals only consider child related signs, as they have little contact with parents. However, other professionals think it's important to consider signs originating from the parent, as children cannot express their feelings properly. Finally, many professionals rely on their gut feeling without being aware of specific signs.

Knowledge. Primary school professionals know the different types of child abuse, but are not able to name signs corresponding to these different types. Most professionals are aware of the reporting guidelines, but are not able to name the specific steps and some professionals have insufficient knowledge to follow the guidelines. In pre-service training of professionals, child abuse was not addressed. However, most professionals followed a (mandatory) in-service course on detecting child abuse and the reporting guidelines, which increased their child abuse related knowledge.

Risk Perception. In primary schools, adequately assessing the risk of child abuse was considered difficult by professionals. School counselors mention that they depend on the detection and risk assessment skills of teachers, simply because the latter have more direct contact with children. Finally, culture is mentioned as a factor that may complicate risk assessments. A professional said: "In some cultures it is very normal to spank a child".

\subsubsection{High School Professionals}

Cues to Action. High school professionals especially mention child related signs, including high absenteeism rates, poor school results, physical signs (e.g., bruises, scratches on the arm) and bringing no food to school. Some professionals consider the parent-child interaction as an important source, although no specific interaction related sings were mentioned. Parent related signs are almost never mentioned, due the lack of contact with parents. One professional did consider parents in the detection of potential signs and said: "We want to see the parents at least three times a year, otherwise we go on a home visit".

Knowledge. The professionals are aware of the different types of child abuse and are able to identify the corresponding signs. Sexual abuse is considered the most difficult abuse type to detect. Professionals are aware of the reporting guidelines, however they are not able to specify the individual steps. Most professionals think that they have enough knowledge to follow the reporting guidelines, but this was difficult in some complex cases. Most professionals mentioned that child abuse as a topic was not part of their pre-service education, but some professionals (not the teachers) followed extra courses on child abuse. These courses provided professionals with more knowledge and skills about detecting and reporting abuse.

Risk Perception. Three professionals experienced difficulties with assessing the risk of child abuse. Professionals consider it important to take cultural differences and cultural norms and values into account in risk assessments. 


\subsection{Motivation Phase}

According to the I-Change a person's intention to perform a specific behavior is influenced by several motivational factors such as a person's attitude, social influences, and self-efficacy. Figure 2 describes the results of this study as related to the motivation phase of the I-Change model.

\subsubsection{CHC Professionals}

Attitude. CHC professionals consider in particular preventing and detecting child abuse as important tasks in their work, because they are socially close to the children and families they work with. The professionals indicate that attention should be paid to the detection of child abuse in every consultation. However, they consider other professionals, such as youth and family workers, more proficient in detecting child abuse, simply because the latter have more contact with the children and their families. $\mathrm{CHC}$ professionals believe that, when there are suspicions of child abuse, each CHC professional is responsible for following the steps of the child abuse reporting guidelines. Sometimes professionals follow the steps together with a child abuse expert in their organization.

Social Influences. When professionals have suspicions of child abuse, they generally feel supported by their organizations. Most of the times, professionals are able to consult colleagues, discuss their suspicions in a team of other professionals, or seek advice from a child abuse expert in their organization about how to handle or proceed with their child abuse suspicions. The child abuse expert is seen as a very valuable colleague, as professionals experience a low threshold to consult such an expert. However, the professionals generally think that the child abuse expert should be consulted more often by $\mathrm{CHC}$ professionals. Further, although professionals are allowed to participate in child abuse courses and education programs, they are insufficiently trained in how to talk to parents and children about signs or suspicions of child abuse. As for the experiences of professionals with the Dutch CPS, professionals are somewhat positive about the advice they receive. One professional said: "When I have doubts about whether or not child abuse is taking place, it helps that I can discuss my doubts with CPS". However, other professionals are more negative about the advice from CPS, as in some cases they did not receive clear guidelines on how to proceed whereas in other cases CPS only confirmed what the professionals already knew themselves. Furthermore, some professionals do not trust CPS in handling child abuse reports correctly. This feeling is reinforced by difficulties in contacting CPS, the long waiting lists, and communication styles of CPS that are experienced as ineffective by the professionals.

Self-Efficacy. All professionals consider detecting signs and assessing the presence and the risk of child abuse to be difficult, and they all believe that they are not able to detect all signs of child abuse in their daily work. However, they do feel competent in applying the steps of the child abuse reporting guidelines because of their experience with child abuse cases in practice, the support they get from their organization, or because the steps of the reporting guidelines have been implemented in the electronic systems they work with.

\subsubsection{Mental Health Care Professionals}

Attitude. Most professionals consider detecting child abuse as very important, but this is not considered as their own task. One professional said: "We are very engaged in the problems of the individual patient, and therefore it's impossible to also be aware of the system around the patient". Furthermore, most mental health care professionals do not have contact with the patient's children and have no knowledge about the family system. Professionals think that outpatient care professionals are responsible for detecting child abuse, as they have entry into the patient's home situation and are in direct contact with the children. Some professionals believe that everyone is responsible for following the reporting guidelines. Other professionals believe that they are only responsible for detecting signs, which is the first step of the reporting guidelines, and that the other steps should be performed by specialized clinicians or physicians. 
Social Influences. When professionals have suspicions of child abuse, they feel supported by their direct colleagues, company lawyers, and team leaders. However, the cooperation with and support from other organizations, such as schools, general practitioners, or health centers, is not optimal. There is a strong need for efficient information exchange about a family between the different organizations in order to gain insight into a family's situation. Further, professionals indicate that their experiences with CPS greatly depends on the specific CPS employee they talk to. Some mental health care professionals had positive experiences with reporting child abuse to CPS, as they received sufficient feedback and trusted CPS to follow up the report correctly. Other professionals think that reporting child abuse to CPS is not helpful, because this may lead to severe intervening which could worsen the child's or family's situation. Therefore, they prefer to arrange help themselves instead of reporting child abuse.

Self-Efficacy. Professionals believe they miss signs of child abuse in their daily work, mainly because they are not aware of signs and because they do not have contact with the patients' children. Professionals feel incompetent in following the reporting guidelines and suggest they attend a monthly course to improve their own knowledge and skills.

\subsubsection{Primary School Professionals}

Attitude. Detecting child abuse is considered an important task by all professionals, especially because early detection might prevent or reduce harmful consequences for the child. Professionals believe that teachers play an important role because they are in direct contact with children and parents. As for the reporting guidelines, teachers are considered responsible for detecting child abuse and the other steps are the responsibility of the school counselor or school social worker. Some professionals consider the school principal responsible for following the guidelines.

Social Influences. Professionals feel supported by the school if they want to follow up on suspected child abuse. They experience support from school counselors, child abuse experts and other colleagues. Professionals do not feel supported by the CPS. Schools are often not involved in the reporting process and CPS does not regard school as professional partners. Professionals also mention that they do not trust that CPS will adequately follow up on a report, it takes a long time before CPS intervenes, CPS lacks communication skills, a child abuse case is closed too quickly and CPS do not provide insight into developments in a reported child abuse case. Professionals prefer to organize help themselves instead of reporting to CPS.

Self-Efficacy. Detecting child abuse was considered difficult and signs of child abuse are often missed. This was partially due to a lack of self-esteem of professionals in handling child abuse cases and because children do not disclose child abuse. Professionals think that the latter might be because children do not realize that their home situation is not "normal". For detecting child abuse, school counselors feel that they depend on the teachers as they have more contact with the children. With regard to reporting potential abuse, professionals fear that they will lose the relationship with parents or that a report might worsen the child's situation.

\subsubsection{High School Professionals}

Attitude. All professionals think that detecting child abuse during their work is important, but some professionals mention that their educational tasks have a higher priority. A professional said: "When a child is not doing well, I will initially focus on education as that is my primary task". Most professionals consider themselves responsible for following the reporting guidelines and sometimes a colleague (e.g., a school counselor) is involved in this. Some professionals consider not the school but CPS to be responsible for assessing the nature and severity of child abuse.

Social Influences. In high schools there is little attention for child abuse. The good mentor-students relationship is considered important by high school professionals, as this may promote students to disclose child abuse to their mentor. All professionals feel 
supported by their school if they want to act upon suspicions of potential child abuse. In that case, meetings were organized by the school and professionals felt supported by the school management. Professionals also consulted CPS for advice on handlings child abuse cases. However, this advice is not always helpful and the quality of this advice depends who at the CPS provides the advice. Experiences with filing a report to CPS are mainly negative, as they often do not follow-up on the report, child abuse cases are closed too quickly, and there is no feedback on the progress of a case. High school professionals prefer to organize help themselves. However, when professional are asked whether they have reasons not to report child abuse to CPS they said no, as it might be in the child's best interests.

Self-Efficacy. Many professionals experience problems regarding detection and potentially miss a lot of sings. Professionals also experience difficulties in talking to parents about suspected abuse, partly because they are afraid that parents will respond with anger. A professional said: "My position is twofold. On the one hand I have to gain a student's trust and on the other hand I have to deal with parents who do not see any problems or do not want to follow up on it. I would like to have more support in this".

\subsection{Action Phase}

Finally, in the action phase of the I-Change model, action is determined by several factors. Besides a positive intention, these factors comprise certain performance skills and action planning. Barriers may have a negative effect on transferring intentions into actions. See Figure 3 for an overview of the thematic analysis of concepts related to the action stage of the I-Change model.

\subsubsection{CHC Professionals}

Performance Skills. CHC professionals have sufficient skills to apply the steps of the reporting guidelines, but they also indicate that they have insufficient communication skills to effectively talk with parents or children about child abuse. Professionals think that a specialized communication skills training, in which they learn how to ask the right questions, would be helpful. Assessing the nature and severity of child abuse was also considered difficult, and in particular when clear signs are absent. This sometimes leads to mental pressure for professionals: "You hope that you are making the right choices about whether or not to intervene, but there is a chance that you are too late with your decision to intervene. That risk gives me stress. The questions "should I intervene?", and "how long should I wait?", cause a lot of stress in professionals".

Action Plans. Professionals indicate that a clear and handy overview of child abuse signs (e.g., an information card) could help in detecting child abuse. In addition, the availability of a protocol that structures the conversation between professionals and parents/children is very helpful in detecting parenting problems and development delays of children, and is seen as very supportive in detecting child abuse. Professionals think that they detect more signs when families are seen more often and regularly and when they are more connected to the neighborhood and community. Some professionals use an instrument in the form of a digital platform where different types of professionals can register their concerns about a child. This may help in detecting child abuse more quickly. In assessing the nature and severity of potential child abuse, professionals consult their direct colleagues, the child abuse expert or CPS. Instruments are rarely used in assessing (the risk of) child abuse, though sometimes tools are used to determine more general (developmental) needs of a child. However, professionals think that evidence-based risk assessment instruments would help in assessing the nature and severity of the abuse. Finally, the willingness of parents to accept help is also determinative in the decision to report child abuse. If parents are cooperative, professionals prefer arranging help themselves to reporting the child abuse to CPS.

Barriers. One of the barriers experienced by professionals in detecting and reporting child abuse is the lack of cooperation between different organizations. It is difficult to share information about a child, because of privacy regulations and in many instances, 
there is insufficient time to arrange a good transfer of information with other organizations. Therefore, it is very time consuming for professionals to collect all information that is relevant in a particular case. The above-described digital platform could support the information transfer, but this platform is rarely used by organizations as they are not familiar with this platform. Further, professionals consider the substantial workload and the associated time constraint as a barrier. Consultations with families are generally too short to get to know the family and the limited amount of time makes it very hard for professionals to be alert of potential child abuse signs. One professional said: "A part of me doesn't want to detect signs, because I don't have time for that. When I think about this, I feel ashamed. It is really bad, but it does happen among professionals".

\subsubsection{Mental Health Care Professionals}

Performance Skills. Many mental health professionals feel that they have insufficient skills to make decisions about child abuse. Furthermore, they indicate that they are not able to effectively talk with parents or children about child abuse. Specifically, they are afraid of damaging the therapeutic relationship with the patient when they bring up potential child abuse. All mental health care professionals need more education about the signs of child abuse.

Action Plans. Mental health professionals consider consultations with colleagues helpful in the child abuse detecting or reporting process. Some professionals use an instrument to assess the child's safety, and in some mental health care institutions risk assessment tools were available (e.g., the CARE-NL; De Ruiter et al. 2012) but these are not used. However, there is a need for an instrument with which a more objective assessment of (the risk of) child abuse can be made, and that can be used to determine whether or not a report should be filed. Professionals were asked about the use of the kid check (Augeo 2013), which is a Dutch instrument for professionals working with adult parents to check whether there is a risk for child unsafety. Most mental health care professionals are not familiar with the kid check, but they do ask intake questions that are comparable to the items that are part of this instrument. Professionals think that the kid check should be included in the standard intake. Finally, professionals were not familiar with the platform for registering concerns about a child, but considered a nationwide use of this platform as very valuable for mental health care.

Barriers. Barriers mentioned by mental health care professionals are the fear of losing the therapeutic relationship with patients and the fear that a report to CPS may worsen the child's or family's situation. Furthermore, because of privacy regulations, other organizations cannot always share information about a family. This is especially problematic for the collaboration with general practitioners, as they generally know a lot about a family. Another barrier mentioned by professionals is that they do not have insight into the home situation and therefore have to rely on what patients tell them, although they cannot always be trusted. Additionally, the small number of child abuse reports filed by mental health care professionals is possibly due to underexposure of child abuse in mental health care. One professional said: "We should do more to prevent child abuse and at least know how to deal with signs. I think we miss a lot of signs because we are too focused on the problems of the patients themselves". Finally, an important barrier concerning the cooperation with CPS is that CPS considers starting or ongoing mental health care for parents as sufficient in child abuse cases, even though the mental health care professionals hardly have insight into the safety of the child. A professional said: "I think that CPS is responsible for the child's safety. Only when a child is safe, we can treat the parents. CPS considers our treatment as a factor that ensures child safety. However, treatment does not guarantee direct safety for a child, only long-term safety".

\subsubsection{Primary School Professionals}

Performance Skills. Only a few professionals believe they have enough skills to follow the reporting guidelines. Talking to parents about signs of potential child abuse was considered very difficult. Professionals believe this will jeopardize the relationship with 
the parents. In addition, many professionals lack skills to assess the nature and severity of child abuse.

Action Plans. Professionals assess the nature and severity of potential child abuse together with colleagues. No risk assessment instrument is used and some professionals believe that these instruments may take away the professional's feeling of the responsibility. Furthermore, some professionals believe that these instruments are multi interpretable and that the outcome depends on the person filling out the instrument. It was also mentioned that the context of the child might not be taken into account in risk assessment instruments. However, most professionals think that a risk assessment instrument could help in making a correct assessment of (the risk of) child abuse. Professionals already using risk assessment instruments were positive, as it helped them resolving doubts and estimating the nature and severity of the abuse. As for the reporting guidelines, some professionals mentioned that teachers were not involved in the entire process but only in detecting potential child abuse. This was in order to maintain a good relationship with the parents and the child. However, other professionals mention that they do involve teachers in the entire process, especially because they are close to the child and the parent. A professional said: "We always include the teacher in the conversation with the parent about child abuse signs, as teachers detected these signs and are therefore in the best position to discuss these". Almost all professionals mention that they prefer finding a solution together with parents over reporting child abuse to CPS.

Barriers. Professionals think that they have insufficient communication skills to effectively talk to parents about potential child abuse and believe that they should improve these skills. Furthermore, professionals mention that child abuse is often hidden by parents and children which is considered a barrier for detecting potential abuse. Barriers mentioned for reporting potential abuse are the fear of potential negative consequences of a report for a child and the fear of negative reactions from parents. Professionals are concerned that they might lose contact with parents, which could be a reason not to report abuse in some cases. Furthermore, professionals consider time constraints associated with a child abuse report as a barrier. A professional said: "A follow-up on a report is very time consuming. This will be at the expense of time a can spend on other work". Finally, school counselors think that child abuse signs are missed because teachers are not focused on child abuse and underestimate the severity of problematic situations. The teachers that we interviewed claim that they are consumed by their daily tasks and are therefore not aware of the situation of individual children.

\subsubsection{High School Professionals}

Performance Skills. Most professionals feel they have enough skills to follow the reporting guidelines, but this is very complicated in complex cases. Some professionals consider talking to parents about signs of potential abuse very difficult.

Action Plans. As for detecting child abuse signs, professionals think it is important to create a safe and trusting environment in order for students to disclose child abuse to their teachers or mentors. For assessing the nature and severity of potential child abuse, professionals consulted their team, an exterior care and advice team or the parent-child counselor. Sometimes they use a risk assessment tool, but most do not think these tools help in making an assessment. A professional said: "I would only use an instrument if it is proven to be effective with multiple independent studies with a very high reliability". However, a number of professionals think that such an instrument can be of value. For example, a professional said: "I can use it together with my own clinical assessment in order to critically and objectively look at my own opinion". Finally, professionals were not familiar with the platform for registering concerns about a child.

Barriers. Many professionals find it difficult to define child abuse and decide whether or not to report potential abuse. Furthermore, professionals experience difficulties in talking to parents about child abuse signs. Finally, they think that children do not trust their teachers enough to tell their story and that many children hide child abuse out of fear, shame or loyalty to their parent. 


\subsection{Points for Improvement}

\subsubsection{CHC Professionals}

To improve the child abuse detection and reporting process, $\mathrm{CHC}$ professionals believe it is important to facilitate continuity, so that professionals work with the same families, or to at least make time for an adequate information transfer between professionals. Additionally, $\mathrm{CHC}$ professionals suggested more time with the individual families (i.e., more or longer consults) as well as training in conversation to improve child abuse detection. Furthermore, many professionals mentioned that the communication and information transfer between different organizations must be improved. To improve the collaboration with CPS, it was suggested to increase face-to-face contacts with an assigned CPS employee. Furthermore, CPS should take the input of $\mathrm{CHC}$ professionals more seriously. Finally, the professionals think that complex cases should be handled by more experienced $\mathrm{CHC}$ colleagues.

\subsubsection{Mental Health Care Professionals}

It was suggested that, in adult mental health care, the importance of detecting and reporting child abuse should be emphasized. Furthermore, professionals think they should be more alert to the patient's system, less restrained in the therapeutic relationship, and have more knowledge about signs that might occur during contact with patients. Mental health care professionals also think the cooperation with other organizations should be improved. In addition, according to the professionals, more attention should be drawn to the reporting guidelines and more cases should be discussed within a team or with CPS. Furthermore, professionals need more dialogue and more direct contact with an CPS employee.

\subsubsection{Primary School Professionals}

The primary school professionals consider it important that teachers pay more attention to child abuse, and they should know how to recognize signs and how to deal with child abuse. In addition, there is a need for training or information on the subject of child abuse and the professionals need more communication with CPS. It was suggested to link a permanent CPS employee to each school in order to have more direct contact.

\subsubsection{High School Professionals}

High school professionals believe that more training is needed for teachers in order to better recognize signs and follow the reporting guidelines. For improving child abuse detection and increasing disclosure, professional believe it is important to create a secure and safe school setting. It should be clear for students where they can go if they have problems they want to talk about. Furthermore, professionals believe it is important to keep each other alert. They feel that they have the duty to adhere to the reporting guidelines and that there should be more focus on these guidelines, instead of only focusing on educational tasks. Professionals want more insight into the progress of child abuse cases reported to CPS. Finally, they need more face-to-face contacts with CPS and suggest linking a permanent CPS employee to each school.

\section{Discussion}

The aim of this study was to examine the experiences of healthcare and education professionals in identifying and reporting child abuse and to gain insight into how this process can be improved. Furthermore, we aimed to investigate detection and reporting behaviors of child professionals after the reporting guidelines became effective in the Netherlands on 1 July 2013. To this end, 49 professionals from child health care, adult mental health care, as well as primary and secondary schools were interviewed to gain insight into their experiences with detecting and reporting child abuse. The professionals were also asked about barriers in this process and about how this process can be improved. Following Schols et al. (2013), this behavior was studied using the I-Change model, which is a behavioral change model consisting of the awareness, motivation, and action phase. Below we will discuss the findings in accordance with these three phases, and the most 
important similarities and differences between the different types of professionals are highlighted. The current findings are also compared to the findings of Schols et al. (2013) to investigate to what extent professionals' detection and reporting behaviors have changed after the reporting guidelines became effective.

As for the awareness phase, professionals mention that child abuse signs originate from various sources, but most professionals mainly pay attention to child related signs. However, research shows that abuse is not always visible at child level and that child abuse is often underestimated when children do not show (behavioral) problems or other direct signs (Trench and Griffiths 2014; Youth Care Inspectorate 2016). Therefore, being aware of parent related signs is very important. Moreover, parent related risk factors are essential in risk assessment as they are more predictive of child abuse than child related risk factors (Assink et al. 2016, 2019; Mulder et al. 2018; Stith et al. 2009). Our findings emphasize the importance of educating professionals on the most important signs and risk factors for child abuse. CHC professionals should also be educated in the essential difference between signs and risk factors, as these terms are often mixed up. Signs of child abuse are used in assessing the child's immediate safety (safety assessment), whereas risk factors are important in determining the risk of future child abuse (risk assessment; Van der Put et al. 2018). The results also revealed that mental health care professionals are often unaware of direct child abuse signs and that child abuse detection is not a central task in mental health care. This is in line with previous research, showing that the reporting guidelines are rarely used in Dutch mental health care organizations (Health Care Inspectorate 2017). The implementation of the mandatory reporting guidelines and the kid check do not seem to have led to greater awareness of child abuse related signs among mental health professionals.

Professionals experience difficulties in following the reporting guidelines and most professionals lack child abuse related knowledge due to insufficient child abuse education. This was also found in previous qualitative studies (Feng et al. 2010; Feng and Wu 2005; Lee et al. 2007; Schols et al. 2013), reporting that both pre-service and in-service child abuse education was inadequate for different types of professionals. Finally, we found that all professionals experience difficulties in estimating the risk of child abuse. For example, $\mathrm{CHC}$, primary school and high school professionals mentioned that cultural differences in norms and values complicate their risk assessment, and primary school counselors depend on teachers for an adequate risk assessment, as the latter are in direct contact with children.

As for the motivation phase of the I-Change model, similarities were found between the professional groups in their attitude towards detecting child abuse. Most professionals considered the detection of child abuse signs an important task in their daily work. However, detecting and handling potential child abuse was often regarded as the responsibility of other professionals (i.e., outpatient care professionals or CPS professionals) or other professionals were viewed as more proficient. An individual sense of responsibility is very important and has a major effect on the detection and reporting behaviors of professionals (Crenshaw et al. 1995; Zellman 1990). It is therefore very important to increase the professionals' sense of responsibility. Moreover, all professionals interviewed in this study are by Dutch law required to follow the reporting guidelines and to take necessary efforts in detecting child abuse (Ministry of Health, Welfare and Sport 2013).

Across professionals there were also similarities in perceived support. Direct colleagues were considered the most important source of support, which was in line with findings from Schols et al. (2013). The support from CPS was often perceived as low and collaborations with CPS were generally perceived as negative, partially due to communication issues and the limited insight professionals have in a reported child abuse. Finally, all professionals revealed a low sense of self-efficacy in detecting child abuse. They all believed that relevant child abuse signs are being missed. Further, primary school professionals indicated feeling insecure about handling child abuse cases, and mental health professionals feel unable to detect child abuse signs due to their lack of insight into the patient's family system. These findings indicate that major gains can be made in professionals' child abuse detection. 
In the action phase, all professionals revealed having a lack in communication skills to effectively discuss potential child abuse signs with a child or parents. Therefore, training in communication skills is very important so that the detection and prevention of child abuse is improved, which was also implied in previous research (Schols et al. 2013; Visscher and Van Stel 2017). As a strategy for detecting or acting upon child abuse signs, most professionals consulted direct colleagues. Screening or risk assessment instruments were hardly used, but professionals do indicate that these instruments would be very helpful in their decision making. In this line, research has showed that future child abuse can be better predicted using actuarial risk assessment instruments than the clinical judgement of professionals (Van der Put et al. 2017), so in particular actuarial instruments can support professionals in risk assessment of child abuse. Further, the previously mentioned digital platform for registering concerns about children and the kid check, which are both prescribed in the mandatory reporting guidelines (Ministry of Health, Welfare and Sport 2013), were not used and some professionals were not even familiar with these instruments. This was also found in recent evaluation studies examining the use of these instruments (Ridderbos-Hovingh et al. 2020; Woestenburg et al. 2020). Therefore, the awareness of these instruments should be increased and the use hereof should promoted within the organizations the professionals work at.

Finally, in the action phase, several barriers were mentioned in detecting and reporting child abuse, such as the fear that filing a CPS report may worsen the child's or family's situation (mental health and primary school professionals); the fear of deteriorating the relationship with the parents of losing contact with them (mental health and primary school professionals); time constrains (CHC and primary school professionals), and deficits in the cooperation with other organizations (CHC and mental health care professionals). These barriers were also found in previous qualitative studies (Gilbert et al. 2009b; Greco et al. 2017; Kenny 2004; Schols et al. 2013).

In comparing our results with those of Schols et al. (2013), who studied detecting and reporting behaviors of professionals prior to the mandatory reporting guidelines became effective, we found important similarities. Both studies show a lack of pre-service and in-service education about the signs of child abuse and conversation skills. The mandatory reporting guidelines did not seem to have contributed to more attention and training on these subjects. More knowledge and training, however, significantly increase the intention of professionals to act upon suspicions of child abuse (Feng and Wu 2005; Pietrantonio et al. 2013). Our results show that training is especially important for mental health care professionals, as child abuse is underexposed in mental health care institutions, and emphasizing the importance of detecting and reporting child abuse was seen as an important area for improvement. Mental health care professionals are essential in the detection and reporting process because they have insight into important parent related factors, such as psychiatric disorders or substance abuse, which are important predictors for child abuse.

Our own findings and those of Schols et al. (2013) indicate that there is a strong need for structured detection and risk assessment tools, which support professionals in assessing the nature and severity of potential child abuse. Over the years, many risk assessment instruments have been developed in the Netherlands, such as the LIRIK (Ten Berge and Eijgenraam 2014), the Child Abuse Risk Evaluation-Netherlands (CARENL; De Ruiter et al. 2012) and the ARIJ (Van der Put et al. 2015). However, these tools have been developed for and used in the context of child welfare. Yet, no tools are available for risk assessment in other settings, such as schools or mental health care. Therefore, it is important to develop new risk assessment instruments, or to modify existing instruments, specifically for the use in these settings. Furthermore, it is important to distinguish between three types of instruments: (1) safety assessment instruments for determining whether or not child abuse is currently present; (2) risk assessment instruments for estimating the risk of future child abuse; and (3) needs assessment instruments for determining the dynamic risk factors that can be addressed in interventions (Van der Put et al. 2018). Knowing the 
difference between these types of assessment is essential for professionals, as direct action must be taken in case of child unsafety.

The similarities between our findings and those of Schols et al. (2013) indicate that the implementation of the mandatory reporting guidelines in the Netherlands did not seem to have influenced the detection and reporting behaviors of healthcare and education professionals and the barriers they experience herein. The mandatory guidelines were recently evaluated by Ridderbos-Hovingh et al. (2020) and corresponding to our findings, they emphasized the importance of training in child abuse sign recognition and found that professionals experienced barriers in discussing suspicions of child abuse with parents or children. These researchers indicate that professionals may have the false idea that the aim of such a discussion with parents is to eventually file a child abuse report to CPS, whereas the actual aim is to identify child abuse sings and to give parents or children the opportunity to respond to potential suspicions. Additionally, in line with our findings, the researchers found that CPS does not provide insight into the progress of a child abuse report and that professionals do not trust that CPS adequately follows up on a report. According to Ridderbos-Hovingh et al. (2020), the latter was due to incorrect expectations of the tasks of CPS and they suggest that professionals should be better informed about the role of the CPS.

There are several limitations that need to be addressed. First, we sampled professionals who were willing to participate voluntarily, and thus we have a selected sample. These professionals may have been more motivated and interested in the topic child abuse than the average professional in their field. Therefore, it could be possible that selection bias is present. Second, the results of this study cannot be generalized to professionals working in other fields in which the reporting guidelines were also implemented, such as doctors, general practitioners, child daycare staff, and midwives. Finally, the non-experimental research design does not allow us to draw conclusions about the causality. To examine the actual effect of the mandatory reporting guidelines on how child abuse is detected and reported, a quantitative research design is needed. However, the exploratory nature of this study provides directions for future research. For example, future research should examine the effect of more or improved child abuse education for professionals on child abuse detection and reporting.

\section{Conclusions}

In conclusion, detecting and reporting child abuse is considered very important by child professionals in the Netherlands. However, there are differences in how this is done across types of professionals. Further, several barriers were identified that stand in the way of an optimal detection and reporting of child abuse, such as deficits in the cooperation with other organizations and time constrains. Our results show that improvements in child abuse detection and reporting could be reached through: (1) developing tools for detecting and assessing the risk of child abuse in the context of schools, child health care and mental health care; (2) developing clear protocols for detection and reporting procedures; (3) strongly integrating child abuse in pre-service training and improving (or more frequently offer) current in-service training about signs of child abuse and conversation skills to discuss these signs with parents or children; (4) improving organizational support for professionals to make them feel more competent with reporting and detecting abuse; and (5) improving communication and information transfer between organizations, especially with CPS. These are important implications for policy and practice. The fact that the current findings are largely in line with the findings of Schols et al. (2013) who studied the detection and reporting of child abuse prior to the implementation of the mandatory reporting guidelines, suggests that the detecting and reporting behaviors of professionals have barely changed. However, behavioral change is needed for a more efficient and effective prevention of child abuse. The recommendations from this study should therefore be taken into account by policymakers and politicians in future plans aimed at reducing or preventing child abuse in the Netherlands. 
Author Contributions: Conceptualization, C.E.v.d.P. and J.G.; methodology, C.E.v.d.P. and J.G.; validation, J.G., C.E.v.d.P. and M.A.; formal analysis, J.G.; investigation, J.G.; resources, C.E.v.d.P.; writing—original draft preparation, J.G.; writing—review and editing, C.E.v.d.P., P.P., M.A. and J.G.; supervision, C.E.v.d.P., P.P. and M.A.; project administration, C.E.v.d.P.; funding acquisition, C.E.v.d.P. All authors have read and agreed to the published version of the manuscript.

Funding: This research was funded by ZonMw, grant number 741100002.

Institutional Review Board Statement: Not applicable.

Data Availability Statement: Not applicable.

Conflicts of Interest: The authors declare no conflict of interest.

\section{References}

Ajzen, Icek. 1991. The theory of planned behavior. Organizational Behavior and Human Decision Processes 50: 179-211. [CrossRef]

Alink, Lenneke R. A., Dante Cicchetti, Jungmeen Kim, and Fred A. Rogosch. 2012. Longitudinal associations among child maltreatment, social functioning, and cortisol regulation. Developmental Psychology 48: 224-36. [CrossRef]

Alink, Lenneke R. A., Mariëlle Prevoo, Sheila van Berkel, Mariëlle Linting, Mariska K. Velderman, and Fieke Pannebakker. 2018. NPM-2017: Nationale prevalentiestudie mishandeling van kinderen en jeugdigen [National Prevalence Study abuse Children and Youth]. Leiden: Leiden University, Available online: https:/ /www.rijksoverheid.nl/binaries/rijksoverheid/documenten/rapporten/20 19/02/05/nationale-prevalentiestudie-mishandeling-van-kinderen-en-jeugdigen/nationale-prevalentiestudie-mishandelingvan-kinderen-en-jeugdigen.pdf (accessed on 2 February 2020).

Assink, Mark, Claudia E. van der Put, Kimberly Kuiper, Tim Mulder, and Geert-Jan J. M. Stams. 2016. Risicofactoren voor kindermishandeling: Een meta-analytisch onderzoek naar risicofactoren voor seksuele mishandeling, fysieke mishandeling en verwaarlozing [Child abuse Risk Factors: A Meta-Analytic Study of Risk Factors for Sexual abuse, Physical abuse, and Neglect]. Amsterdam: University of Amsterdam, Available online: https:/ / pure.uva.nl/ws / files / 6636742/Onderzoeksrapport_Risicofactoren_voor_Kindermishandeling.pdf (accessed on 17 March 2018).

Assink, Mark, Claudia E. van der Put, Mandy M. W. C. Meeuwsen, Nynke M. de Jong, Frans J. Oort, Geert-Jan J. M. Stams, and Machteld Hoeve. 2019. Risk factors for child sexual abuse victimization: A meta-analytic review. Psychological Bulletin 145: 459-89. [CrossRef]

Augeo. 2013. Handleiding Kindcheck [Manual Child Check]. Driebergen: Augeo, Available online: https://www.augeo.nl/-/media/ Files/Kindcheck/Augeo-Handleiding-Kindcheck.ashx (accessed on 5 January 2020).

Bandura, Albert. 1986. Social Foundations of Thought and Action: A Social Cognitive Theory. Englewood Cliffs: Prentice-Hall.

Boeije, Hennie. 2009. Analyseren in kwalitatief onderzoek: Denken en doen [Analyzing in Qualitative Research: Thinking and Doing]. Amsterdam: Boom Lemma Uitgevers.

Cerezo, M. Angeles, and Gemma Pons-Salvador. 2004. Improving child maltreatment detection systems: A large-scale case study involving health, social services, and school professionals. Child Abuse \& Neglect 28: 1153-69.

Chang, David C., Vinita Misra, Susan Ziegfeld, Adil Haider, Dawn Warfield, and Charles Paidas. 2004. The Tip of the Iceberg for Child Abuse: The Critical Roles of the Pediatric Trauma Service and its Registry. The Journal of Trauma 57: 1189-98. [CrossRef] [PubMed]

Cheung, Kei Long, Santiago Hors-Fraile, and Hein de Vries. 2021. How to use the Integrated-Change Model to design digital health programs. In Digital Health. Amsterdam: Elsevier, pp. 143-57.

Child Welfare Information Gateway. 2019. Mandatory Reporters of Child Abuse and Neglect. Child Welfare Information Gateway. Available online: https:/ / www.childwelfare.gov/pubPDFs/manda.pdf (accessed on 13 February 2021).

Cicchetti, Dante. 2016. Socioemotional, personality, and biological development: Illustrations from a multilevel developmental psychopathology perspective on child maltreatment. Annual Review of Psychology 67: 187-211. [CrossRef]

Crenshaw, Wesley B., Lucinda M. Crenshaw, and James W. Lichtenberg. 1995. When educators confront child abuse: An analysis of the decision to report. Child Abuse \& Neglect 19: 1095-113.

De Haan, Irene, Eileen Joy, Liz Beddoe, and Sark Iam. 2019. “The tip of the iceberg": Multiple thresholds in schools' detecting and reporting of child abuse and neglect. Children and Youth Services Review 96: 278-85. [CrossRef]

De Ruiter, Corine, Martin Hildebrand, and Steven van der Hoorn. 2012. Gestructureerde risicotaxatie bij kindermishandeling: De Child Abuse Risk Evaluation-Nederlandse versie (CARE-NL) [Gestructureerde risicotaxatie bij kindermishandeling: De Child Abuse Risk Evaluation-Nederlandse versie (CARE-NL)]. GZ—Psychologie 4: 10-17. [CrossRef]

De Vries, Hein, Ilse Mesters, Hermanna van de Steeg, and Cora Honing. 2005. The general public's information needs and perceptions regarding hereditary cancer: An application of the Integrated Change Model. Patient Education and Counseling 56: 154-65. [CrossRef]

De Vries, Hein. 2017. An integrated approach for understanding health behavior: The I-Change Model as an example. Psychology and Educational Science International Journal 2. [CrossRef]

Eggers, Sander M., Leif E. Aarø, Arjan E. R. Bos, Catherine Mathews, and Hein de Vries. 2014. Predicting Condom Use in South Africa: A Test of Two Integrative Models. AIDS and Behavior 18: 135-45. [CrossRef] 
European Union Agency for Fundamental Rights. 2017. Provisions on Professionals' Legal Obligation to Report Cases of Child abuse, Neglect and Violence. Vienna: European Union Agency for Fundamental Rights, Available online: http://fra.europa.eu/en/publication/ 2015/mapping-child-protection-systems-eu/reporting-1 (accessed on 13 February 2021).

Feng, Jui-Ying, and Yo-Wu B. Wu. 2005. Nurses' intention to report child abuse in Taiwan: A test of the theory of planned behavior. Research in Nursing \& Health 28: 337-47.

Feng, Jui-Ying, Tzu-Yi Huang, and Chi-Jen Wang. 2010. Kindergarten teachers' experience of reporting child abuse in Taiwan. Child Abuse \& Neglect 34: 124-28.

Fraser, Jennifer A., Ben Mathew, Kerryann Walsh, Linping Chen, and Michael Dunne. 2010. Factors influencing child abuse and neglect recognition and reporting by nurses: A multivariate analysis. International Journal of Nursing Studies 47: 146-53. [CrossRef] [PubMed]

Gilbert, Ruth, Cathy Spatz Widom, Kevin Browne, David Fergusson, Elspeth Webb, and Steffan Janson. 2009a. Burden and consequences of child maltreatment in high-income countries. Lancet 373: 68-81. [CrossRef]

Gilbert, Ruth, June Thoburn, Alison Kemp, Peter Sidebotham, Lorraine Radford, Danya Glaser, and Harriet L. Macmillan. 2009b. Recognising and responding to child maltreatment. Lancet 373: 167-80. [CrossRef]

Goebbels, Adrienne F. G., Jan M. Nicholson, Kerryann Walsh, and Hein de Vries. 2008. Teachers' reporting of suspected child abuse and neglect: Behaviour and determinants. Health Education Research 23: 941-51. [CrossRef]

Greco, Ana M., Geogina Guilera, and Naomí Pereda. 2017. School staff members experience and knowledge in the reporting of potential child and youth victimization. Child Abuse E Neglect 72: 22-31.

Health Care Inspectorate. 2017. Meldcode huiselijk geweld en kindermishandeling: Het bewustzijn groeit, maar nog niet overall [Reporting Code for Domestic Violence and Child Abuse: Awareness Is Growing, But Not Yet Everywhere]. Den Haag: Ministry of Health, Wellbeing and Sport, Available online: https:/ /www.igj.nl/binaries/igj/documenten/rapporten/2017/07/07/meldcode-huiselijk-geweldkindermishandeling-bewustzijn-groeit/Meldcode+huiselijk+geweld+en+kindermishandeling_+het+bewustzijn+groeit\%2C+ maar+nog+niet+overal.pdf (accessed on 29 June 2020).

Janz, Nancy K., and Marshall H. Becker. 1984. The Health Belief Model: A Decade Later. Health Education E Behavior 11: 1-47.

Jonson-Reid, Melissa, Patricia L. Kohl, and Brett Drake. 2012. Child and adult outcomes of chronic child maltreatment. Pediatrics 129: 839-45. [CrossRef]

Kenny, Maureen C. 2004. Teachers' attitudes toward and knowledge of child maltreatment. Child Abuse E Neglect 28: 1311-19.

Ketterer, Frederic, Linda Symons, Marie-Claire Lambrechts, Philippe Mairiaux, Lode Godderis, Lieve Peremans, Roy Remmen, and Marc Vanmeerbeek. 2014. What factors determine Belgian general practitioners' approaches to detecting and managing substance abuse? A qualitative study based on the I-Change Model. BMC Family Practice 15: 119. Available online: https: //bmcfampract.biomedcentral.com/articles/10.1186/1471-2296-15-119 (accessed on 13 January 2020). [CrossRef] [PubMed]

Kinderrechtencolleftief. 2011. De aanpak van kindermishandeling in Nederland: Knelpunten en aanbevelingen [The Approach to Child abuse in the Netherlands: Bottlenecks and Recommendations]. Leiden: Kinderrechtencollectief, Available online: https://www. dekinderombudsman.nl/system/files/inline/2011Rapportkindermishandelingkinderrechtencollectieftbvkinderombudsman. pdf (accessed on 13 January 2020).

Konijnendijk, Annemieke A. J., Magda M. Boere-Boonekamp, Riet M.E. Haasnoot-Smallegange, and Ariana Need. 2014. A qualitative exploration of factors that facilitate and impede adherence to child abuse prevention guidelines in Dutch preventive child health care. Journal of Evaluation in Clinical Practice 20: 417-24. [CrossRef] [PubMed]

Lane, Wendy G., and Howard Dubowitz. 2007. What factors affect the identification and reporting of child abuse-related fractures? Clinical Orthopaedics and Related Research 461: 219-25. [CrossRef]

Lee, Pei-Yu, Jennifer A. Fraser, and Fan-Hao Chou. 2007. Nurse Reporting of Known and Suspected Child Abuse and Neglect Cases in Taiwan. The Kaohsiung Journal of Medical Sciences 23: 128-37. [CrossRef]

Locke, Edwin A., and Gary P. Lathan. 1991. A Theory of Goal Setting \& Task Performance. The Academy of Management Review 16: 480-83.

Ministry of Health, Welfare and Sport. 2013. Model Reporting Code Domestic Violence and Child Abuse; Den Haag: Ministry of Health, Welfare and Sport. Available online: https://www.government.nl/binaries/government/documents/reports/2013/03/14 /model-reporting-code-domestic-violence-and-child-abuse/domestic-violence-and-child-abuse.pdf (accessed on 13 January 2020).

Mulder, Tim M., Kimberly C. Kuiper, Claudia E. van der Put, Geert-Jan J. M. Stams, and Mark Assink. 2018. Risk factors for child neglect: A meta-analytic review. Child Abuse \& Neglect 77: 198-210.

Pietrantonio, Anna M., Elise Wright, Kathleen N. Gibson, Tracy Alldred, Dustin Jacobson, and Anne Niec. 2013. Mandatory reporting of child abuse and neglect: Crafting a positive process for health professionals and caregivers. Child Abuse and Neglect 37: 102-9. [CrossRef]

Prochaska, James O., and Carlo C. DiClemente. 1983. Stages and processes of self-change of smoking: Toward an integrative model of change. Journal of Consulting and Clinical Psychology 51: 390-95. [CrossRef]

Reijneveld, Sijmen A., G. de Meer, Carin H. Wiefferink, and Matty R. Crone. 2008. Detection of child abuse by Dutch preventive child-healthcare doctors and nurses: Has it changed? Child Abuse and Neglect 32: 831-37. [CrossRef] [PubMed]

Ridderbos-Hovingh, Chantal M., Brenda J. M. Frederiks, Christine Veen, A. Tingen, Mark Beukers, J. Bieuwe Geertsema, P. H. H. van Dijk, Nicolette O. M. Woestenburg, and Heinrich B. Winter. 2020. Evaluatie Wet verplichte meldcode huiselijk geweld en kindermishandel- 
ing [Evaluation of the Mandatory Reporting Code Act for Domestic Violence and Child abuse]. Den Haag: ZonMw, Available online: https: / / www.rijksoverheid.nl/binaries/rijksoverheid/documenten/rapporten/2020/04/30/evaluatie-wet-verplichte-meldcodehuiselijk-geweld-en-kindermishandeling/evaluatie-wet-verplichte-meldcode-huiselijk-geweld-en-kindermishandeling.pdf (accessed on 14 July 2020).

Schellingerhout, Roelof, and Clarie Ramakers. 2016. Scholierenonderzoek Kindermishandeling 2016 [Student Study Child abuse]. Nijmegen: Radboud Universiteit Nijmegen, Available online: https:/ / www.rijksoverheid.nl/binaries/rijksoverheid/documenten/ rapporten/2017/03/31/scholierenonderzoek-kindermishandeling-2016/scholierenonderzoek-kindermishandeling-2016.pdf (accessed on 2 February 2020).

Schols, Manuela W., Corine de Ruiter, and Ferko G. Öry. 2013. How do public child healthcare professionals and primary school teachers identify and handle child abuse cases? A qualitative study. BMC Public Health 13: 807. Available online: https: // bmcpublichealth.biomedcentral.com/articles/10.1186/1471-2458-13-807 (accessed on 1 February 2020). [CrossRef]

Segaar, Dewi, Catherine Bolman, Marc C. Willemsen, and Hein de Vries. 2006. Determinants of adoption of cognitive behavioral interventions in a hospital setting: Example of a minimal-contact smoking cessation intervention for cardiology wards. Patient Education and Counseling 61: 262-71. [CrossRef] [PubMed]

Stith, Sandra M., Ting Liu, L. Christopher Davies, Esther L. Boykin, Meagan C. Alder, Jennifer M. Harris, Anurag Som, Mary McPherson, and J. E. M. E. G. Dees. 2009. Risk factors in child maltreatment: A meta-analytic review of the literature. Aggression and Violent Behavior 14: 13-29. [CrossRef]

Strauss, Anselm L., and Juliet Corbin. 2007. Basics of Qualitative Research: Techniques and Procedures for Developing Grounded Theory. Thousand Oaks: Sage.

Ten Berge, Ingrid, and Karin Eijgenraam. 2014. Licht Instrument Risicotaxatie Kindveiligheid (LIRIK): Toelichting en instructie 2014 [Light Instrument for Child Safety Risk Assessment (LIRIK): Explanation and instruction 2014]. Utrecht: Nederlands Jeugdinstituut, Available online: https:/ / www.nji.nl/nl/Download-NJi/Publicatie-NJi/LIRIK-2014-toelichting-en-instructie.pdf (accessed on 2 February 2021).

The Council of Australian Governments. 2009. Protecting Children is Everyone's Business-National Framework for Protecting Australia's Children 2009-2020; Canberra: The Council of Australian Governments. Available online: https://www.google.nl/url?sa=t\&rct= $\mathrm{j} \& \mathrm{q}=\&$ esrc $=\mathrm{s} \& \mathrm{frm}=1 \&$ source=web\&cd $=4 \&$ ved $=0 \mathrm{CD} 0 \mathrm{QFj}$ AD\&url=https $\% 3 \mathrm{~A} \% 2 \mathrm{~F} \% 2 \mathrm{Fwww} \cdot \operatorname{coag} \cdot$ gov.au $\% 2 \mathrm{Fsites} \% 2 \mathrm{Fdefault} \%$ 2Ffiles\%2Fchild_protection_framework.rtf\&ei=8b6bVcW5G4TyUv_-gbgL\&usg=AFQjCNEnAPK5x4sG8hheCZk_uxe8ZCcQhA (accessed on 13 February 2021).

Trench, Sally, and Sian Griffiths. 2014. Serious case Review: Family L.. Norfolk: Norfolk Safeguarding Children Board, Available online: https:/ / www.norfolklscb.org/wp-content/uploads/2015/03/Norfolk-SCR_Case-L_FINAL.pdf (accessed on 13 February 2020).

Van der Put, Claudia E., Mark Assink, and Geert-Jan J. M. Stams. 2015. Actuarieel Risicotaxatie Instrument voor Jeugdbescherming (ARIJ): Eindrapport [Actuarial Risk Assessment Instrument for Youth Protection (ARIJ): Final Report]. Amsterdam: University of Amsterdam, Available online: https:/ / dare.uva.nl/search?identifier=c4077be6-3063-4ac1-a912-00e23a4656c7 (accessed on 13 March 2017).

Van der Put, Claudia E., Mark Assink, and Noelle F. Boekhout van Solinge. 2017. Predicting child maltreatment: A meta-analysis of the predictive validity of risk assessment instruments. Child Abuse $\mathcal{E}$ Neglect 73: 71-88.

Van der Put, Claudia E., Mark Assink, Jeanne Gubbels, Judith van Lent, and Geert-Jan J. M. Stams. 2018. De ontwikkeling van ARIJ-Needs: Een instrument voor behoeftetaxatie in jeugdbescherming [The Development of ARIJ-Needs: An Instrument for Needs Assessment in Youth Protection]. Amsterdam: University of Amsterdam, Available online: https:/ / dare.uva.nl/search?identifier=0ed3c274-3240-491a8d94-95cf91f8eda8 (accessed on 20 May 2019).

Visscher, Simeon J.A., and Henk F. Van Stel. 2017. Variation in prevention of child maltreatment by Dutch child healthcare professsionals. Child Abuse \& Neglect 70: 264-73.

Webster, Stephen W., Richard O'Toole, Anita W. O'Toole, and Betsy Lucal. 2005. Overreporting and underreporting of child abuse: Teachers' use of professional discretion. Child Abuse E Neglect 29: 1281-96.

Woestenburg, N.O.M., V.E.T. Dörenberg, C. Veen, P. H. H. van Dijk, J.B. Geertsema, M. Beukers, C. M. Ridderbos-Hovingh, and H.B. Winter. 2020. Tweede evaluatie: Wet verwijsindex risicojongeren [Second Evaluation: Youth Risk Reference Index Act]. Den Haag: ZonMw, Available online: https: / www.rijksoverheid.nl/binaries/rijksoverheid/documenten/rapporten/2020/04/30/tweede-evaluatiewet-verwijsindex-risicojongeren/tweede-evaluatie-wet-verwijsindex-risicojongeren.pdf (accessed on 14 July 2020).

Youth Care Inspectorate. 2016. Casusonderzoek Drenthe-Onderzoek naar aanleiding van het overlijden van een kind [Case Study Drenthe-Research into the Death of a Child]. Utrecht: Youth Care Inspectorate, Available online: https://www.inspectie-jenv. $\mathrm{nl} /$ binaries/inspectie-venj/documenten/rapporten/2016/05/27/casusonderzoek-drenthe---onderzoek-naar-aanleiding-vanhet-overlijden-van-een-kind/Casusonderzoek+Drenthe+-+Onderzoek+naar+aanleiding+van+het+overlijden+van+een+kind . pdf (accessed on 14 July 2020).

Zellman, Gail L. 1990. Child Abuse Reporting and Failure to Report among Mandated Reporters: Prevalence, Incidence, and Reasons. Journal of Interpersonal Violence 5: 3-22. [CrossRef] 